\title{
Recent results of primary transnasal surgery for infradiaphragmatic craniopharyngioma
}

\section{Takumi Abe, M.D., Ph.D., and Dieter K. Lüdecke, M.D.}

Department of Neurosurgery, Showa University School of Medicine, Tokyo, Japan; and Department of Neurosurgery, Pituitary Surgery Unit, University Hospital Eppendorf, Hamburg, Germany

Results of primary transnasal surgery were evaluated in 35 patients (18 males and 17 females) with intrasellar and suprasellar craniopharyngiomas treated between 1985 and 1996 when more refined surgical and diagnostic techniques were available. Patients ranged in age from 8 to 72 years (mean 27 years); 14 patients were younger than 18 years of age. The transnasal approach was chosen because of sellar enlargement and presence of infradiaphragmatic tumor. The paramedian portion of the normal pituitary gland was incised vertically to reach a dorsally located tumor in 25 patients. Complete tumor resection was achieved in 15 patients and subtotal removal in 19; in one patient, only aspiration of cyst contents was performed. Tumor regrowth was seen in three patients after subtotal removal; in two, total tumor removal was achieved by a second transnasal surgery, whereas radiotherapy was administered in the other. In a single patient, total tumor removal was achieved by a second transcranial surgery after cyst aspiration. The duration of the clinical follow-up period was at least 1 year. Persistent diabetes insipidus appeared after total tumor resection in five patients. Cerebrospinal fluid leakage occurred in three patients, with two requiring revision. Among 29 patients with preoperatively normal pituitary functions, $20(69 \%)$ were preserved after primary total resection, whereas six (19.4\%) of 31 previously disturbed functions were normalized. After subtotal removal including cyst aspiration, $39(88.6 \%)$ of 44 normal functions were preserved, whereas nine (24.3\%) of 37 disturbed functions were normalized. The transnasal approach should be the first choice in infradiaphragmatic craniopharyngiomas with sellar enlargement in cases in which the extrasellar portion is mostly cystic and is accessible. The concept of subtotal removal with preservation of pituitary functions, especially when treating craniopharyngioma in children, seems to be justified.

Key Words * craniopharyngioma * infradiaphragmatic tumor * pituitary function * primary transnasal surgery

The surgical approach of choice for craniopharyngioma, still a matter of debate, is determined by the location and extent of the tumor. Craniotomy via various routes is most commonly used for removal of tumors located in the suprasellar region.[21,23,24] A transsphenoidal approach is chosen when a craniopharyngioma is located either totally or partially within an enlarged sella turcica and has only a limited suprasellar component; several small series concerning this topic have been published.[1,4,7-9,11,13,14,16,20] The anatomical situation makes it more difficult to avoid further damage to the pituitary gland with total tumor removal because the gland has to be incised or dislocated 
to access the tumor. Since 1971 we have subtotally resected most of the latter-described tumors via a transnasal approach; the senior author has published the results over the period of 1971 to 1984.[14] Magnetic resonance (MR) imaging, which provides detailed information about tumor location and extent,[22] is extremely helpful in planning the surgical approach. Moreover, pressure-irrigation-suction systems and mirror techniques allow removal of extrasellar tumor components under visual control.[19] To evaluate the effectiveness of improved transnasal microsurgery in our recent cases, we analyzed the results of primary transnasal surgery for intrasellar and suprasellar infradiaphragmatic craniopharyngiomas.

\section{CLINICAL MATERIAL AND METHODS}

\section{Patient Population}

One hundred twenty-six patients with a histologically confirmed craniopharyngioma underwent surgery at Hamburg University or at the Marienkrankenhaus in Hamburg from January 1985 to December 1996. We review a series of 35 consecutive patients $(27.8 \%)$ among this group who underwent primary transnasal surgery, including 18 males and 17 females ranging in age from 8 to 72 years (mean \pm standard error, $26.9 \pm 2.7$ ). Fourteen patients were younger than 18 years of age. None had undergone any previous surgery or radiotherapy.

\section{Clinical Symptoms}

The preoperative duration of symptoms due to tumor varied between 3 weeks and 11 years (mean $2.1 \pm$ 0.4). Principal signs and symptoms included chiasmatic syndromes such as temporal visual field defects in 18 patients and headache in 16 . Hypogonadism was the predominant symptom in patients aged 18 years and older, affecting 12 of these 21 patients. Growth delay was the most common symptom in patients younger than 18 years of age, occurring in nine of 14. Four of these nine patients also experienced pubertal delay. Eight patients manifested diabetes insipidus to varying degrees, based on total fluid intake, urine volume, morning urine specific gravity, and clinical criteria, including history. Water-deprivation testing was performed in some borderline cases. Eight patients presented with secondary amenorrhea and two with galactorrhea.

\section{Endocrinological Findings}

Endocrinological findings were assessed on the basis of baseline hormonal levels (normal range: prolactin, 1.5-20 ug/L; adrenocorticotropic hormone [ACTH], 30-60 pg/mL; thyroid-stimulating hormone [TSH], 0.3-3.4 $\mu \mathrm{U} / \mathrm{mL}$; luteinizing hormone, 6-34 mIU/mL; and follicle-stimulating hormone, $2-22 \mathrm{mIU} / \mathrm{mL}$ ) and endocrine stimulation tests as needed. For assessment of the hypothalamic-pituitary-adrenal axis (adrenocorticotropic function), dynamic testing was performed with either corticotropin-releasing hormone stimulation or insulin-induced hypoglycemia and the serum cortisol response measured. For evaluation of the thyroid and gonadal function, dynamic testing with thyrotropin-releasing hormone and gonadotropin-releasing hormone stimulation was performed. Growth hormone $(\mathrm{GH})$ secretion was judged on the basis of endocrinological testing (insulin tolerance test, GH-releasing hormone test, or arginine test), because growth can be normal or even excessive in patients with craniopharyngioma, even if their pituitary gland produces no GH.[2] Nine children showed GH deficiency. Hyperprolactinemia was observed in 13 patients. Further assessment of anterior pituitary function showed adrenal insufficiency in 18, thyroid insufficiency in 10, and gonadal insufficiency in 18 patients (Table 1). 


\begin{tabular}{|c|c|c|c|c|}
\hline \multicolumn{5}{|c|}{$\begin{array}{c}\text { PRE- AND POSTOPERATIYE ENDOCR NOLOGKAL FIND NGS IN PR MARY TOTAL AND } \\
\text { SUBTOTAL REMOYAL OF CRANIOPHARYNGIOMA }\end{array}$} \\
\hline \multirow[b]{3}{*}{ Arterior Pitulary Function } & \multirow[b]{3}{*}{ Preop } & \multicolumn{2}{|c|}{ No. of Patierts } & \\
\hline & & & Postop & \\
\hline & & Nomal & Atnormal & No Data \\
\hline \multicolumn{5}{|c|}{ complete tumor remo val (15 patients) } \\
\hline $\begin{array}{l}\text { normal } \\
\text { subnormal } \\
\text { no data. } \\
\text { crolactin }\end{array}$ & $\begin{array}{l}7 \\
7 \\
1\end{array}$ & $\begin{array}{l}7 \\
0 \\
1\end{array}$ & $\begin{array}{l}0 \\
7 \\
0\end{array}$ & $\begin{array}{l}0 \\
0 \\
0\end{array}$ \\
\hline $\begin{array}{l}\text { normal } \\
\text { elevated } \\
\text { no data } \\
\text { adrenocorticotronic hormone }\end{array}$ & $\begin{array}{l}7 \\
4 \\
4\end{array}$ & $\begin{array}{l}7 \\
3 \\
1\end{array}$ & $\begin{array}{l}0 \\
1 \\
0\end{array}$ & $\begin{array}{l}0 \\
0 \\
3\end{array}$ \\
\hline $\begin{array}{l}\text { normal } \\
\text { subnormal } \\
\text { no data. }\end{array}$ & $\begin{array}{l}5 \\
8 \\
2\end{array}$ & $\begin{array}{l}1 \\
0 \\
2\end{array}$ & $\begin{array}{l}4 \\
5 \\
0\end{array}$ & $\begin{array}{l}0 \\
3 \\
0\end{array}$ \\
\hline $\begin{array}{l}\text { thyrotropic hormone } \\
\text { normal } \\
\text { subnormal } \\
\text { no data. } \\
\text { gonadotro pic hormone }\end{array}$ & $\begin{array}{l}7 \\
4 \\
4\end{array}$ & $\begin{array}{l}4 \\
0 \\
1\end{array}$ & $\begin{array}{l}2 \\
4 \\
0\end{array}$ & $\begin{array}{l}1 \\
0 \\
3\end{array}$ \\
\hline $\begin{array}{l}\text { normal } \\
\text { subnormal } \\
\text { no data. }\end{array}$ & $\begin{array}{l}3 \\
8 \\
4\end{array}$ & $\begin{array}{l}1 \\
3 \\
1\end{array}$ & $\begin{array}{l}2 \\
3 \\
0\end{array}$ & $\begin{array}{l}0 \\
2 \\
3\end{array}$ \\
\hline \multicolumn{5}{|c|}{ subtotal tumor removal (20 patients) } \\
\hline $\begin{array}{l}\text { normal } \\
\text { subnormal } \\
\text { no data }\end{array}$ & $\begin{array}{r}13 \\
2 \\
5\end{array}$ & $\begin{array}{r}13 \\
0 \\
3\end{array}$ & $\begin{array}{l}0 \\
2 \\
0\end{array}$ & $\begin{array}{l}0 \\
0 \\
2\end{array}$ \\
\hline $\begin{array}{l}\text { prolactin } \\
\text { normal } \\
\text { elevated } \\
\text { no data. } \\
\text { adrenocorticotropic hormone }\end{array}$ & $\begin{array}{l}8 \\
9 \\
3\end{array}$ & $\begin{array}{l}8 \\
4 \\
3\end{array}$ & $\begin{array}{l}0 \\
5 \\
0\end{array}$ & $\begin{array}{l}0 \\
0 \\
0\end{array}$ \\
\hline $\begin{array}{l}\text { normal } \\
\text { sutnormal } \\
\text { no data. }\end{array}$ & $\begin{array}{r}8 \\
10 \\
2\end{array}$ & $\begin{array}{l}6 \\
2 \\
0\end{array}$ & $\begin{array}{l}2 \\
6 \\
0\end{array}$ & $\begin{array}{l}0 \\
2 \\
2\end{array}$ \\
\hline $\begin{array}{l}\text { thyrotropic hormone } \\
\text { normal } \\
\text { subnormal } \\
\text { no data. } \\
\text { gonadotro pic hormone }\end{array}$ & $\begin{array}{r}10 \\
6 \\
4\end{array}$ & $\begin{array}{l}7 \\
1 \\
1\end{array}$ & $\begin{array}{l}2 \\
4 \\
1\end{array}$ & $\begin{array}{l}1 \\
1 \\
2\end{array}$ \\
\hline $\begin{array}{l}\text { normal } \\
\text { sutnormal } \\
\text { no data. }\end{array}$ & $\begin{array}{r}5 \\
10 \\
5\end{array}$ & $\begin{array}{l}5 \\
2 \\
0\end{array}$ & $\begin{array}{l}0 \\
8 \\
0\end{array}$ & $\begin{array}{l}0 \\
0 \\
5\end{array}$ \\
\hline
\end{tabular}

\section{Radiological Findings}

Polytomography scanning showed an enlarged sella turcica in all but one patient and incomplete sphenoid pneumatization in six children. Six patients were studied preoperatively by computerized tomography (CT) scanning, and 29 patients by MR imaging. Radiological examination demonstrated primarily intrasellar masses with moderate suprasellar extension, and an intact diaphragm stretched upward by the tumor in all but one patient. The masses measured between $10 \mathrm{~mm}$ and $40 \mathrm{~mm}$ in diameter (mean $21.9 \pm 1.2$ ). The principal mass was exclusively intrasellar in two (Fig. 1), intrasellar and 
suprasellar in 32 (Figs. 2-4), and suprasellar only in one patient. Calcifications (Fig. 4) were found in 13 craniopharyngiomas, and cysts were observed in all. Magnetic resonance $\mathrm{T}_{1}$-weighted imaging demonstrated a high-intensity cystic tumor in 20 patients and a low-intensity cystic tumor in nine.

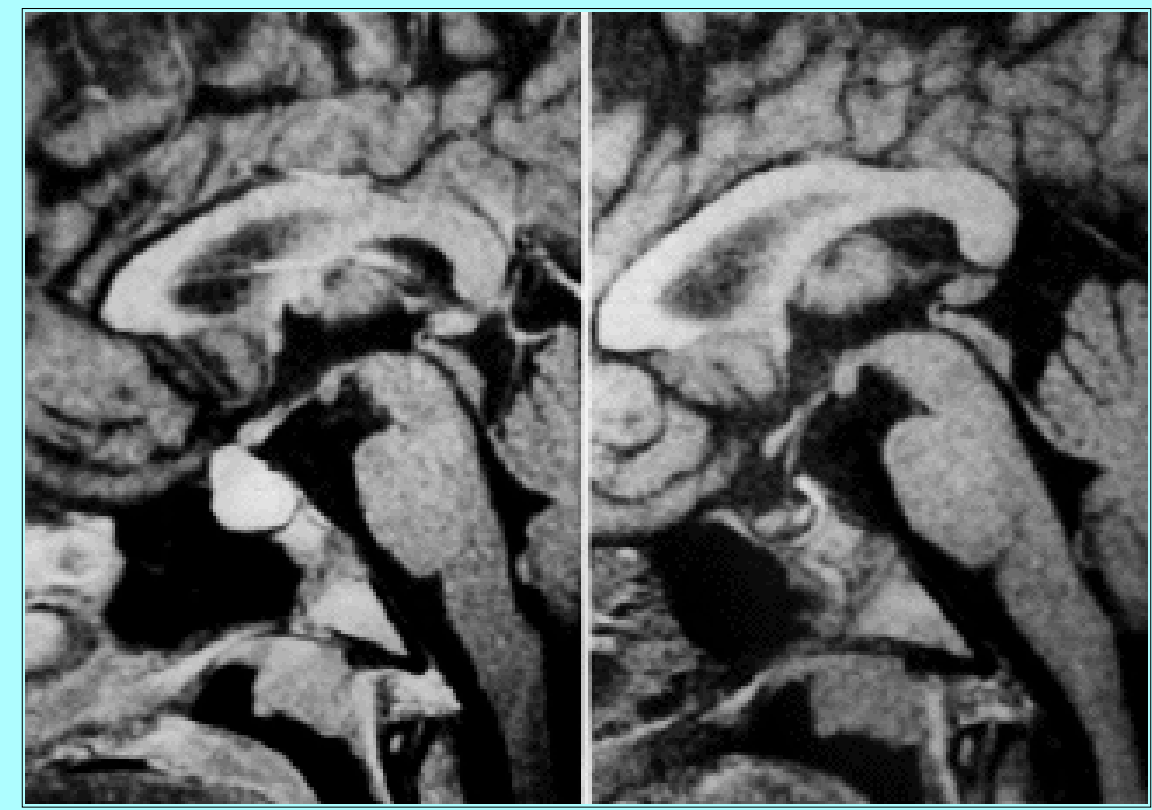

Fig. 1. Images obtained in a 13-year-old girl with diabetes insipidus. Left: Preoperative sagittal $\mathrm{T}_{1}$-weighted MR image revealing a high-intensity intrasellar cystic mass. Right: Postoperative image, 2 years after transnasal surgery, showing complete excision of a craniopharyngioma, with preservation of the pituitary gland and stalk.

\section{Transnasal Surgery}

In general, when a craniopharyngioma produces enlargement of the sella, its origin is likely to be intrasellar, below the diaphragm. [10,11] The transnasal approach was chosen when the infradiaphragmatic tumor was located entirely or partly in an enlarged sella and no significant parasellar extension was present. The operative technique representing the transnasal approach to the sellar region has been described in detail elsewhere.[18] In six patients with incomplete pneumatization of the sphenoid bone, adequate exposure was achieved by drilling of the sphenoid (Table 2). In most patients, after achieving wide opening of the dura, the anterior pituitary gland was seen anteriorly within the sella, and the paramedian portion of the normal gland was vertically incised and mobilized laterally to reach the dorsally located tumor. The capsule of the craniopharyngioma behind the pituitary gland then was exposed and opened. After intracapsular debulking, the tumor capsule was dissected from surrounding structures such as the pituitary gland, cavernous sinus, and diaphragma sellae, and the residual capsule was coagulated. The pituitary stalk was not sacrificed in any patient, although sharp dissection of the capsule from the stalk was necessary in some. In addition to intraoperative evaluation by the surgeon, the extent of tumor resection was estimated by postoperative MR imaging. 
TABLE 2

FINDINGS IN PATIENTS TREATED WITH TRANSNASAL SURGERY

\begin{tabular}{cc|}
\hline \hline Finding & No. of Patierts \\
\hline sphenoid sinus & \\
conchal type & 4 \\
presellar type & 2 \\
pituitary gland & 25 \\
anterior to tum or & 10 \\
superior to tumor & 17 \\
cyst content & 18 \\
"machine oil" & \\
cholesterin &
\end{tabular}

\section{Follow-Up Review}

Postoperative endocrinological and ophthalmological evaluations were performed beginning 1 week after surgery. Repeated MR imaging was performed 6 months or less after surgery. For further follow-up review, all patients were seen by referring endocrinologists and pediatricians. The patients were followed clinically and radiologically for 12 to 136 months (mean $24.1 \pm 4.7$ months).
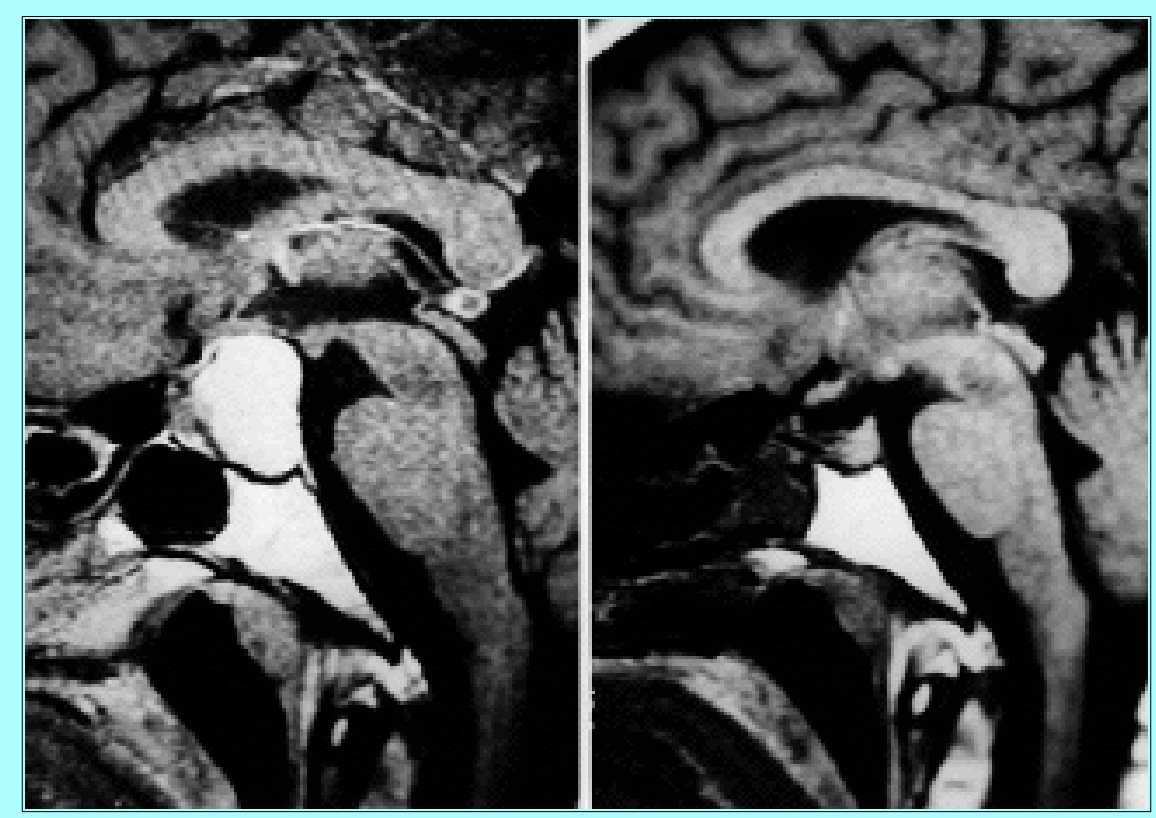

Fig. 2. Images obtained in a 46-year-old man with hypogonadism, visual disturbance, and headache. Left: Preoperative sagittal $\mathrm{T}_{1}$-weighted MR image revealing a high-intensity intrasellar and suprasellar cystic tumor, which anteriorly displaces the normal pituitary gland. Right: Postoperative image, 3 years after transnasal surgery, showing total tumor removal, with preservation of the pituitary gland and stalk.

\section{RESULTS}

\section{Surgical Findings}

Surgical findings are shown in Table 2. The thinned bone of the sellar floor and basal sellar dura were intact in all patients. In 25 patients $(71.4 \%)$, normal pituitary tissue was recognized anterior to the tumor within the sella after opening the dura, and in all of these patients the gland had to be incised and dislocated in order to reach the craniopharyngioma. In 10 patients, the cysts were located immediately 
adjacent to the basal dura, and cyst fluid spilled out when the dura was incised. In such patients, the normal gland was found superiorly to the tumor. The cyst contents had the characteristic "machine oil" appearance in 17 patients and a somewhat purulent appearance approximating cholesterin in 18 others. In two patients, the craniopharyngioma was exclusively intrasellar. Radical removal of the tumor at first operation, with preservation of the normal gland and stalk, was possible in these patients (Fig. 1). In 32 patients, the tumor was intrasellar and suprasellar. Complete removal of the intracapsular tumor and the entire capsule was obtained in 13 patients (Fig. 2); in 19, removal was subtotal (near total). In the latter patients, a portion of the tumor capsule remained in a retrosellar pouch of the diaphragm, and the residual capsule was coagulated (Figs. 3 and 4).

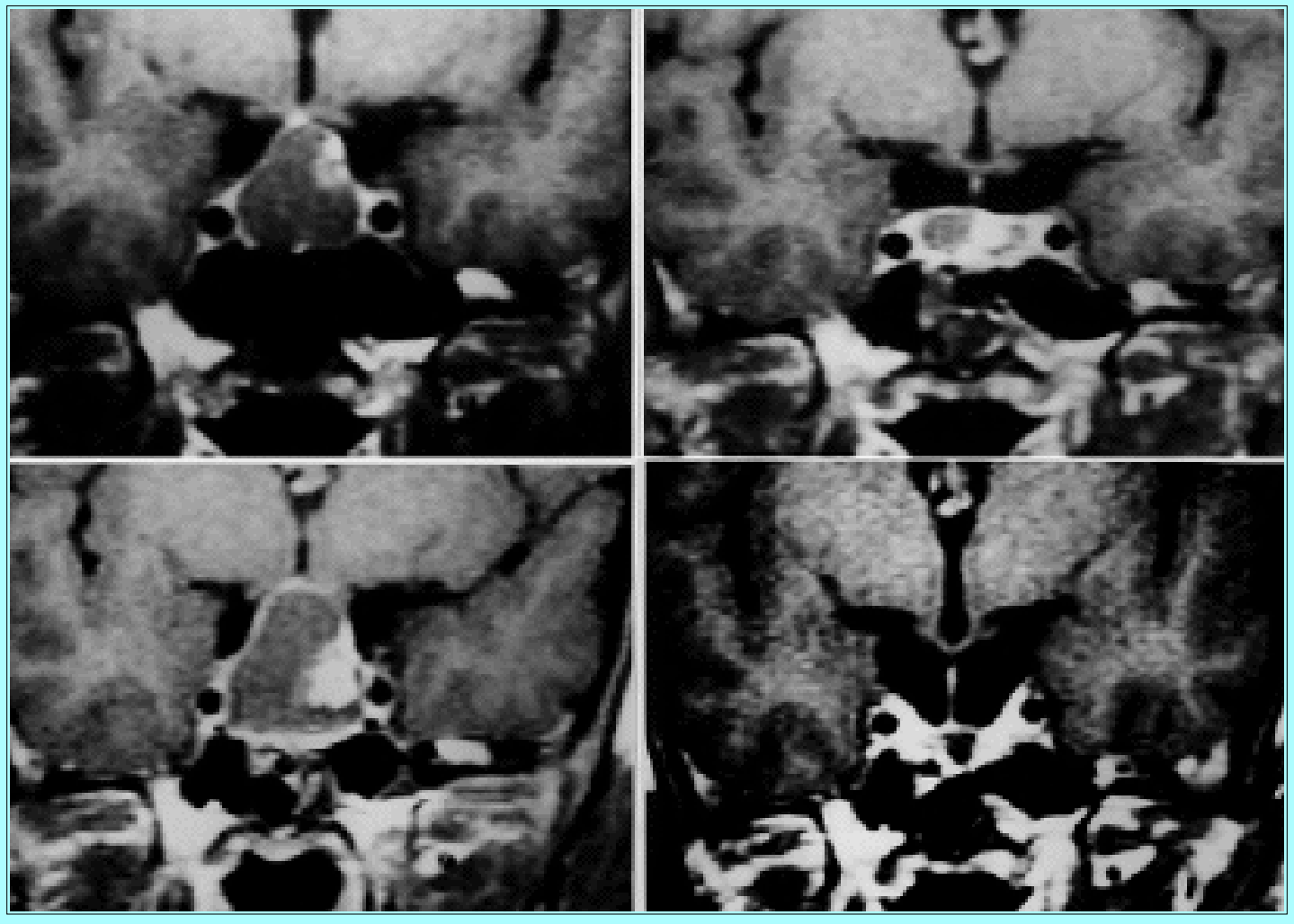

Fig. 3. Images obtained in an 18-year-old woman with secondary amenorrhea and visual disturbance. Upper Left: Preoperative enhanced coronal $\mathrm{T}_{1}$-weighted MR image revealing a low-intensity intrasellar and suprasellar cystic tumor with a small area of high intensity that was subtotally removed via the transnasal route. Upper Right: Postoperative image, 6 months after surgery, showing residual tumor. Lower: Images demonstrating regrowth of the residual tumor 1 year after surgery (left) and showing no evidence of tumor recurrence 2 years after second total resection (right).

In five of 13 patients with suprasellar calcifications, the calcifications were completely removed. In one patient, the tumor was located immediately above the sella and diaphragm. Because of poor clinical condition and severe visual deterioration, cyst aspiration was performed by a transnasal approach. Six months later the residual suprasellar tumor mass was completely removed by the transcranial route. In all patients, the diagnosis of craniopharyngioma was confirmed histologically by the same pathologist. 


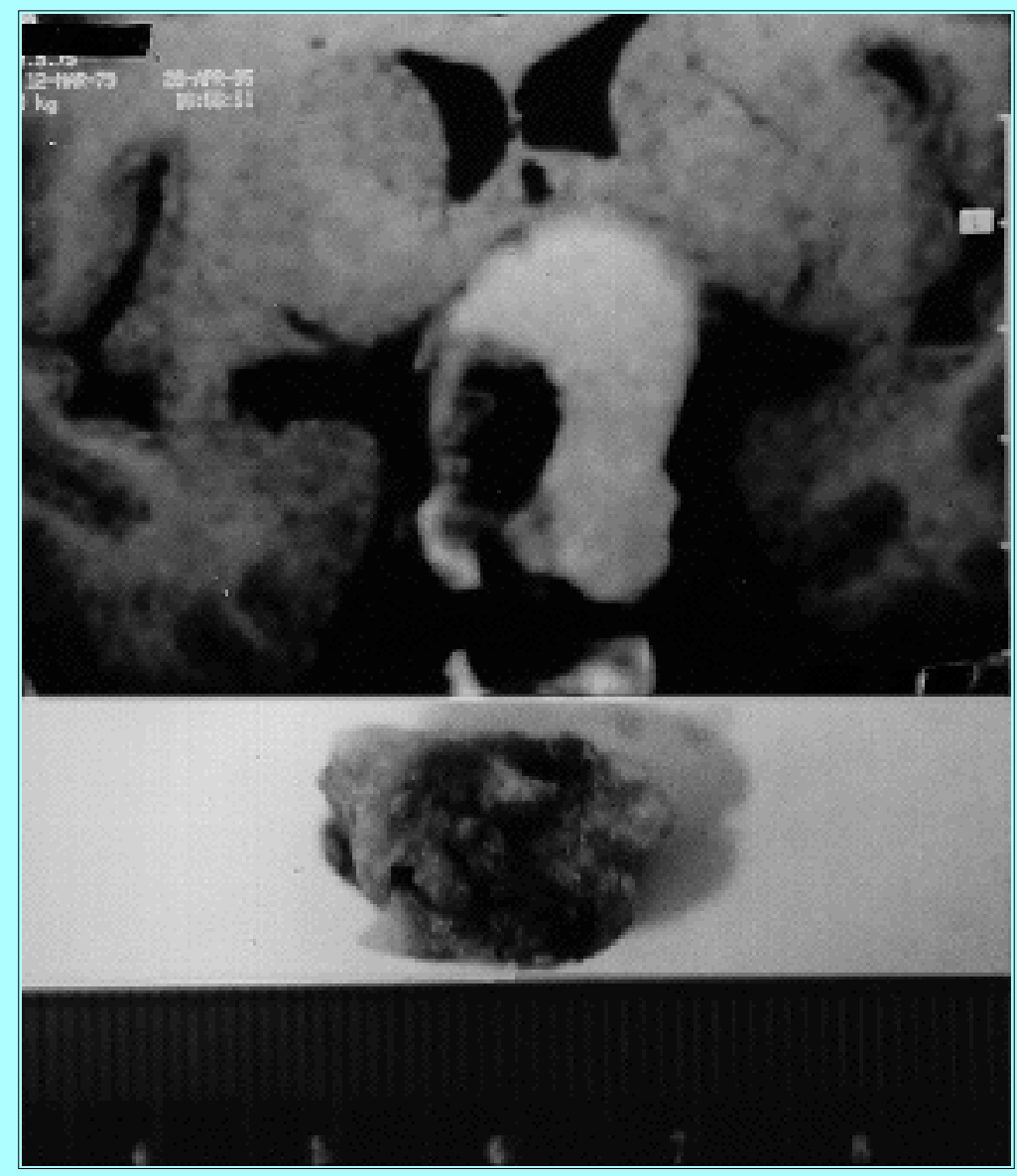

Fig. 4. Images obtained in a 16-year-old girl with visual disturbance and headache. Upper: Preoperative coronal $\mathrm{T}_{1}$-weighted MR image revealing a large, high-intensity intrasellar and suprasellar cystic mass with a large low-intensity area representing calcification. This craniopharyngioma and large calcification were completely resected. Postoperative MR imaging 2 years after surgery showed no evidence of tumor regrowth (not illustrated). Lower: Specimen photograph displaying the large calcification, which was totally removed.

\section{Surgical Complications}

Postoperative cerebrospinal fluid (CSF) leakage occurred in three patients. Two patients had undergone complete removal of an intrasellar and suprasellar tumor and required revision via the transnasal route because of the CSF leakage. In one patient with subtotal tumor removal, CSF leakage resolved after continuous lumbar drainage maintained for 72 hours. Postoperative nasal bleeding occurred in two patients and was controlled with nasal tampons. No operative deaths occurred in this series.

\section{Postoperative Endocrinological Findings}

Postoperative endocrinological findings according to total and subtotal removal (including cyst aspiration) via primary transnasal surgery for craniopharyngiomas are shown in Table 1. Regardless of the degree of surgical resection, GH secretion remained normal in all 20 previously normal patients; GH secretion was postoperatively deficient in all nine children with GH deficiency prior to surgery. Prolactin secretion remained normal in all 15 previously normal patients. A postoperative normalization of excessive prolactin secretion was seen in three $(75 \%)$ of four patients with complete tumor removal, and in four $(44.4 \%)$ of nine with subtotal removal, whereas hyperprolactinemia persisted in six (46.2\%) of 13 previously hyperprolactinemic patients. In four $(80 \%)$ of five patients with total and in two $(25 \%)$ of 
eight with subtotal removal, normal adrenocorticotropic function developed a disturbance postoperatively; normalization was observed in two with subtotal removal. Normal thyrotropic function became disturbed after surgery in two (28.6\%) of seven patients with complete removal and in two (20\%) of 10 with subtotal removal, whereas in one, normalization occurred with subtotal removal. Normal gonadotropic function became abnormal postoperatively in two patients in whom a complete removal was achieved, and in three $(37.5 \%)$ of eight with total and two $(20 \%)$ of 10 with subtotal removal, disturbed gonadotropic function preoperatively showed normalization postoperatively.

In 15 patients in whom complete tumor resection was achieved, 20 (69\%) of 29 preoperatively normal pituitary functions were preserved after the transnasal surgery, whereas six (19.4\%) of 31 previously disturbed functions were normalized. In 20 patients in whom subtotal removal was accomplished, 39 $(88.6 \%)$ of 44 normal pituitary functions were preserved after surgery, whereas nine $(24.3 \%)$ of 37 disturbed functions were normalized.

\section{Recurrence, Regrowth, and Adjuvant Therapy}

No recurrence has been observed in any patient whose tumor was totally removed. Regrowth of the tumor was seen in three patients $(8.6 \%)$ in whom the tumor had been subtotally removed. In two patients, the regrown tumor was completely resected by a second transnasal procedure 12 to 41 months after the first operation (Fig. 3). In one patient, radiotherapy was performed 6 months after surgery; this patient has no evidence of tumor progression 6 years later.

\section{Patient Outcomes}

Fifteen of 18 patients with visual disturbances regained normal visual function, and the remaining 3 showed significant improvement within three months after surgery. Headache completely resolved after surgery in all patients. Eleven patients were found to have newly diagnosed diabetes insipidus after primary surgery. The diabetes insipidus was persistent in five patients; in these five patients, complete tumor resection had been achieved. In eight patients with preexisting diabetes insipidus, the replacement dose of vasopressin could be lowered postoperatively, although diabetes insipidus had not completely resolved. Secondary amenorrhea was improved in six of eight patients. Galactorrhea resolved in two of two patients. Growth delay was still present in nine children after surgery and GH replacement therapy was required. Pubertal delay remained unchanged postoperatively.

\section{DISCUSSION}

Approximately one-third of all craniopharyngiomas reported in the literature involve the pituitary fossa.[1,14,15,20] In our recent series, $27.8 \%$ of all patients with craniopharyngiomas had sellar involvement. The transsphenoidal approach is the optimum procedure for intrasellar and suprasellar infradiaphragmatic craniopharyngiomas. In general, it has been suggested that an enlarged pituitary fossa is a prerequisite for transsphenoidal removal of craniopharyngiomas.[4,9,11,14,16,20] However, Honegger, et al.,[13] have maintained that this notion should be modified, and they frequently found slight or no enlargement of the pituitary fossa in their series. In our series, we noticed that the pituitary fossa was slightly enlarged in most cases. We agree with other authors that this approach should be used for infradiaphragmatic craniopharyngiomas and those encasing optic chiasma, hypothalamus, or vascular structures should not be resected by this procedure.[13,23] However, the same authors also stress that if suprasellar calcifications of craniopharyngiomas are detected, complete tumor resection is unlikely, and a transcranial approach will be necessary to accomplish complete excision. Five of 13 craniopharyngiomas 
with suprasellar calcifications in our series were completely resected transnasally using pressure-irrigation-suction systems and mirror techniques (Fig. 4).

Maira, et al.,[20] have reported that incision of the normal pituitary gland to reach a craniopharyngioma never resulted in major functional damage to the anterior pituitary. In our series, six (24\%) of 25 patients in whom a vertical incision of the pituitary was made to reach a dorsally located tumor had partial pituitary deficiencies involving at least one function; five of these six patients developed adrenocorticotropic dysfunction. Honegger, et al.,[13] found in most of their patients that, after primary transsphenoidal surgery, anterior pituitary function generally was unchanged except for normalization of hyperprolactinemia. As shown in Table $1,59(80.8 \%)$ of 73 preoperatively normal pituitary functions were preserved after primary transnasal surgery, whereas for $15(22.1 \%)$ of 68 with preoperative pituitary dysfunction in at least one axis, functions normalized postoperatively. It is noteworthy that $\mathrm{GH}$ and prolactin secretion remained normal in 20 and 15 preoperatively normal patients, respectively. Postoperative normalization of prolactin secretion was seen in seven $(53.9 \%)$ of 13 patients; it was more frequent in complete tumor removal (75\%) than in incomplete removal (44.4\%). Disturbance of ACTH, $\mathrm{TSH}$, luteinizing hormone, and follicle-stimulating hormone secretion was seen more frequently after complete tumor removal than after incomplete removal. Postoperative normalization of ACTH and TSH secretion was observed only after subtotal resection. Carmel[3] and Laws[17] have observed that careful removal of the tumor capsule does not necessarily cause any additional damage to hypothalamic structures. In our own results, complete tumor removal by the transsphenoidal route carried considerable risk of diabetes insipidus. We have to mention that direct postoperative lumber drainage was not routinely performed. Therefore, in treating childhood craniopharyngioma, relatively conservative surgery may be desirable in order to preserve normal pituitary tissue and avoid a cognitive defect.[5,6] If tumor is found to be adherent to the hypothalamus at operation, we sometimes consider a staged conservative procedure.

Some authors have reported no tumor recurrences after primary complete resection.[13,17,20,24] As an additional evaluation of surgical resection, we have used enhanced MR imaging 6 months after surgery.[12] In our patients with MR-confirmed total resection, no evidence of tumor recurrence has been found during the limited follow-up period. In contrast, regrowth was observed in only three (15.8\%) of 19 patients with incomplete tumor removal, which also involved a lower risk of pituitary damage.

Our study confirms that primary transnasal surgery for infradiaphragmatic craniopharyngiomas with enlarged sella represents the safest approach and is associated with a low operative morbidity. The main disadvantage of this procedure is the risk of CSF leakage. These infradiaphragmatic craniopharyngiomas cannot be compared with supradiaphragmatic craniopharyngiomas, in which total removal by the transcranial route is associated with considerable morbidity and mortality.[24]

Results of primary transnasal microsurgery in two separate series are shown in Table 3 . In the earlier series,[14] reduction of tumor bulk was the aim, accomplished by aspiration of cyst contents or subtotal tumor excision. In patients who underwent aspiration of cyst contents, the suprasellar portion of the tumor was larger than the intrasellar one. After aspiration, ${ }^{90}$ yttrium was implanted into the cyst. Presently, MR imaging provides more detailed information about tumor location and extent[22] and is extremely helpful in choosing the most appropriate surgical approach. Therefore, in this more recent series, total or nearly total tumor removal was intended, whereas mere transnasal cyst aspiration was performed in only one patient in poor general condition who had a suprasellar craniopharyngioma without sellar enlargement. 


\section{RESULTS OF PR MARY TRANSNASAL MICROSURGERY FOR CRANIOPHARYNGIOMS IN TWO SEPARATE SERES}

\begin{tabular}{|c|c|c|c|}
\hline & & $\begin{array}{l}\text { König, et al. } \\
1971-1984\end{array}$ & $\begin{array}{l}\text { Present Series } \\
1985-1996\end{array}$ \\
\hline \multirow{4}{*}{\multicolumn{2}{|c|}{$\begin{array}{l}\text { no. of patients } \\
\text { sex (malefemale) } \\
\text { age range (ys) (mean) }\end{array}$}} & 29 & 35 \\
\hline & & $18: 11$ & $18: 17$ \\
\hline & & $7-48(25)$ & $8-72$ (27) \\
\hline & & & \\
\hline \multirow{2}{*}{$\begin{array}{l}\text { operation } \\
\text { cyst aspiration }\end{array}$} & primary & 7 & 1 \\
\hline & reop & 5 & 1 \\
\hline \multirow[t]{3}{*}{ subtotal removal } & primary & 20 & 19 \\
\hline & reop & 1 & 2 \\
\hline & radiation & 1 & 1 \\
\hline \multirow[t]{2}{*}{ complete removal } & primary & 2 & 15 \\
\hline & reop & 0 & 0 \\
\hline \multirow{4}{*}{$\begin{array}{l}\text { radiation therapy } \\
\text { surgical complications }\end{array}$} & & 1 & 1 \\
\hline & CSF leakage & 2 & 3 \\
\hline & revision & 1 & 2 \\
\hline & $\begin{array}{l}\text { oculomo tor nerve } \\
\text { calsy }\end{array}$ & 1 & 0 \\
\hline \multicolumn{2}{|l|}{ mortality } & 1 & 0 \\
\hline
\end{tabular}

Results of primary transsphenoidal surgery for craniopharyngiomas in other reported series are shown in Table 4. Difficulties arise in comparing our recent series with other reports because of variation in location and extent of tumor, surgical strategy, and follow-up intervals. Nevertheless, our results do not differ greatly from other recent series from academic institutions.

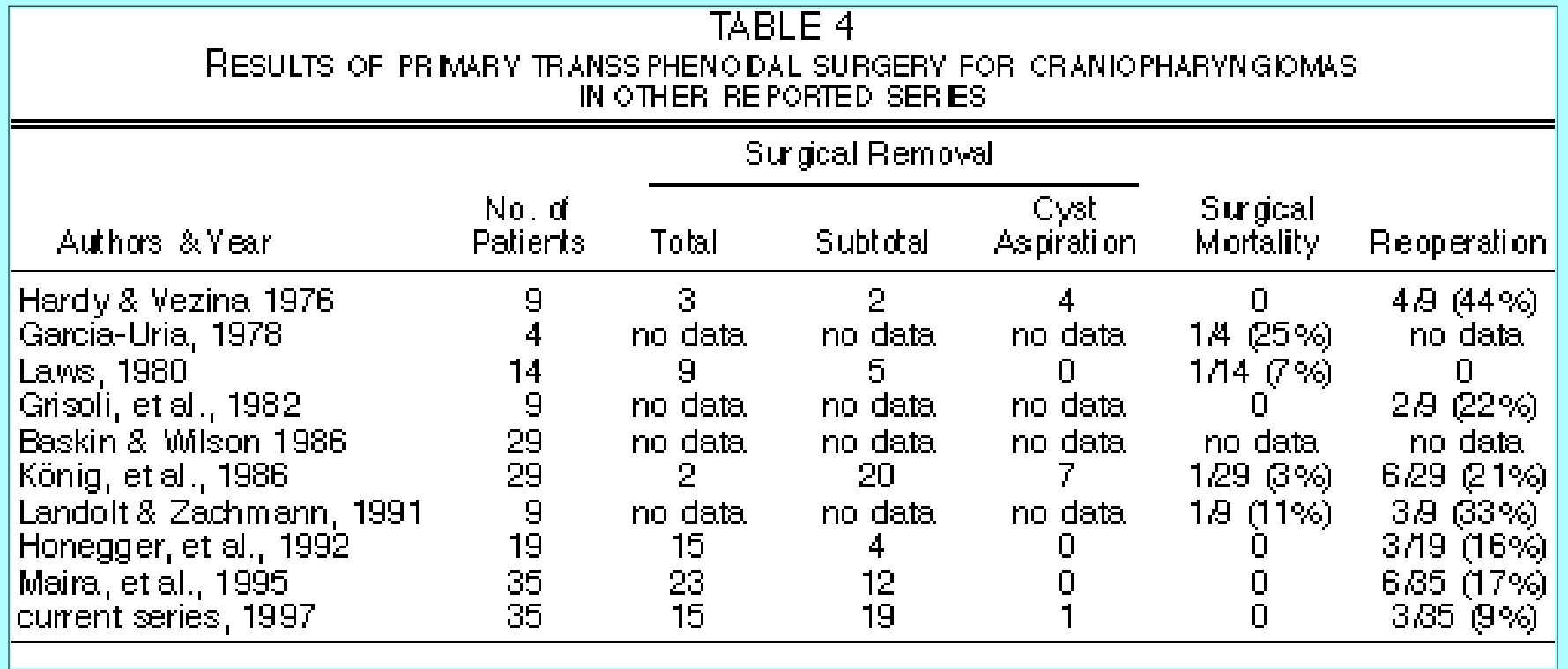

\section{CONCLUSIONS}

In conclusion, the transnasal approach should be the first choice in intrasellar and suprasellar infradiaphragmatic craniopharyngiomas with sellar enlargement if the extrasellar component is mostly cystic and readily accessible. The concept of subtotal tumor excision for better preservation of the pituitary functions, especially when treating childhood craniopharyngiomas, seems to be justified, whereas mere aspiration of cyst contents had a mostly a transitory effect. 


\section{Acknowledgments}

The authors gratefully acknowledge the technical assistance of Mrs. R. Bohlken, Mrs. S. Flügge, Mrs. G. Glagla, and Mrs. E. Lehmann. They particularly wish to thank all the referring endocrinologists and pediatricians for providing meticulous follow-up data, and Dr. W. Saeger (Department of Pathology, Marienkrankenhaus, Hamburg, Germany) for pathological diagnosis. We are indebted to Drs. K. Takakura (Department of Neurosurgery, Tokyo Women's Medical College) and K. Matsumoto (Department of Neurosurgery, Showa University School of Medicine) who encouraged a program of academic and clinical exchange between Tokyo and Hamburg with the generous help of the Japan Brain Foundation.

\section{References}

1. Baskin DS, Wilson CB: Surgical management of craniopharyngiomas. A review of 74 cases. J Neurosurg 65:22-27, 1986

2. Bucher H, Zapf J, Torresani T, et al: Insulin-like growth factors I and II, prolactin, and insulin in 19 growth hormone-deficient children with excessive, normal, or decreased longitudinal growth after operation of craniopharyngioma. N Engl J Med 309:1142-1146, 1983

3. Carmel PW: Craniopharyngiomas, in Wilkins RH, Rengachary SS (eds): Neurosurgery. New York: McGraw-Hill, 1985, Vol 1, pp 905-916

4. Ciric IS, Cozzens JW: Craniopharyngiomas: transsphenoidal method of approach--for the virtuoso only? Clin Neurosurg 27:169-187, 1980

5. De Vile CJ, Grant DB, Kendall BE, et al: Management of childhood craniopharyngioma: can the morbidity of radical surgery be predicted? J Neurosurg 85:73-81, 1996

6. Fischer EG, Welch K, Shillito J Jr, et al: Craniopharyngiomas in children. Long-term effects of conservative surgical procedures combined with radiation therapy. J Neurosurg 73:534-540, 1990

7. Garcia-Uria J: Surgical experience with craniopharyngioma in adults. Surg Neurol 9:11-14, 1978

8. Grisoli F, Vincentelli F, Farnarier P, et al: Trans-sphenoidal microsurgery in the management of non-pituitary tumours of the sella turcica, in Brock M (ed): Modern Neurosurgery. Berlin:

Springer-Verlag, 1982, Vol 1, pp 193-204

9. Hamberger CA, Hammer G, Norlén G, et al: Surgical treatment of craniopharyngioma. Radical removal by the transantrosphenoidal approach. Acta Otolaryngol 52:285-292, 1960

10. Hardy J: Transsphenoidal hypophysectomy. J Neurosurg 34:582-594, 1971

11. Hardy J, Vezina JL: Transsphenoidal neurosurgery of intracranial neoplasm. Adv Neurol 15:261-274, 1976

12. Harwood-Nash DC: Neuroimaging of childhood craniopharyngioma. Pediatr Neurosurg 21 (Suppl 1):2-10, 1994

13. Honegger J, Buchfelder M, Fahlbusch R, et al: Transsphenoidal microsurgery for craniopharyngioma. Surg Neurol 37:189-196, 1992 
14. König A, Lüdecke DK, Herrmann HD: Transnasal surgery in the treatment of craniopharyngiomas. Acta Neurochir 83:1-7, 1986

15. Konovalov AN: Technique and strategies of direct surgical management of craniopharyngiomas, in Apuzzo MLJ (ed): Surgery of the Third Ventricle. Baltimore: Williams \& Wilkins, 1987, pp 542-553

16. Landolt AM, Zachmann M: Results of transsphenoidal extirpation of craniopharyngiomas and Rathke's cysts. Neurosurgery 28:410-415, 1991

17. Laws ER Jr: Transsphenoidal microsurgery in the management of craniopharyngioma. J Neurosurg 52:661-666, 1980

18. Lüdecke DK: Lüdecke Instrumentation for the Direct Transnasal Pituitary Procedure. Hamburg: Waldemar Link, 1986, pp 1-33

19. Lüdecke DK, Treige W: Pressure-irrigation-suction system. Technical note. Acta Neurochir 66:123-126, 1982

20. Maira G, Anile C, Rossi GF, et al: Surgical treatment of craniopharyngiomas: an evaluation of the transsphenoidal and pterional approaches. Neurosurgery 36:715-724, 1995

21. Pang D: Surgical management of craniopharyngioma, in Sekhar LN, Janecka IP (eds): Surgery of Cranial Base Tumors. New York: Raven Press, 1993, pp 787-807

22. Pusey E, Kortman KE, Flannigan BD, et al: MR of craniopharyngiomas: tumor delineation and characterization. AJR 149:383-388, 1987

23. Samii M, Samii A: Surgical management of craniopharyngiomas, in Schmidek HH, Sweet WH (eds): Operative Neurosurgical Techniques: Indications, Methods, and Results, ed 3. Philadelphia: WB Saunders, 1995, Vol 1, pp 357-370

24. Yasargil MG, Curcic M, Kis M, et al: Total removal of craniopharyngiomas. Approaches and long-term results in 144 patients. J Neurosurg 73:3-11, 1990

Manuscript received October 28, 1997.

Accepted in final form November 20, 1997.

Address reprint requests to: Dieter K. Lüdecke, M.D., Department of Neurosurgery, Pituitary Surgery Unit, University Hospital Eppendorf, Martinistrasse 52, 20246 Hamburg, Germany. 